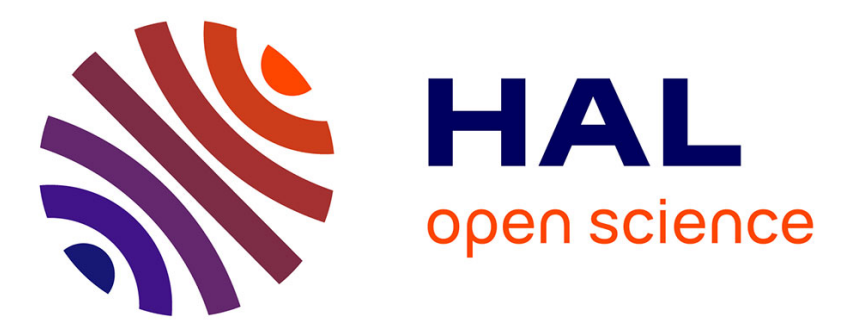

\title{
Insights into the Headgroup and Chain Length Dependence of Surface Characteristics of Organic-Coated Sea Spray Aerosols
}

\author{
S. Cheng, S. Li, N. Tsona, C. George, L. Du
}

\section{> To cite this version:}

S. Cheng, S. Li, N. Tsona, C. George, L. Du. Insights into the Headgroup and Chain Length Dependence of Surface Characteristics of Organic-Coated Sea Spray Aerosols. ACS Earth and Space Chemistry, 2019, 3 (4), pp.571-580. 10.1021/acsearthspacechem.8b00212 . hal-02146490

\section{HAL Id: hal-02146490 \\ https://hal.science/hal-02146490}

Submitted on 28 Nov 2019

HAL is a multi-disciplinary open access archive for the deposit and dissemination of scientific research documents, whether they are published or not. The documents may come from teaching and research institutions in France or abroad, or from public or private research centers.
L'archive ouverte pluridisciplinaire HAL, est destinée au dépôt et à la diffusion de documents scientifiques de niveau recherche, publiés ou non, émanant des établissements d'enseignement et de recherche français ou étrangers, des laboratoires publics ou privés. 
3

14

16

\title{
Insights into the head-group and chain-length dependence of surface characteristics of organic-coated sea spray aerosols
}

\author{
Shumin Cheng, ${ }^{\dagger}$ Siyang Li, ${ }^{\dagger}$ Narcisse T. Tsona, ${ }^{\dagger}$ Christian George, ${ }^{\ddagger, \S}$ and Lin Du*,†
}

${ }^{\dagger}$ Environment Research Institute, Shandong University, Binhai Road 72, Qingdao 266237, China

${ }^{\ddagger}$ School of Environmental Science and Engineering, Shandong University, Binhai Road 72, Qingdao 266237, China

${ }^{\S}$ University of Lyon, Université Claude Bernard Lyon 1, CNRS, IRCELYON, F-69626 Villeurbanne, France

Corresponding author: Email: lindu@sdu.edu.cn, Tel: +86-532-58631980

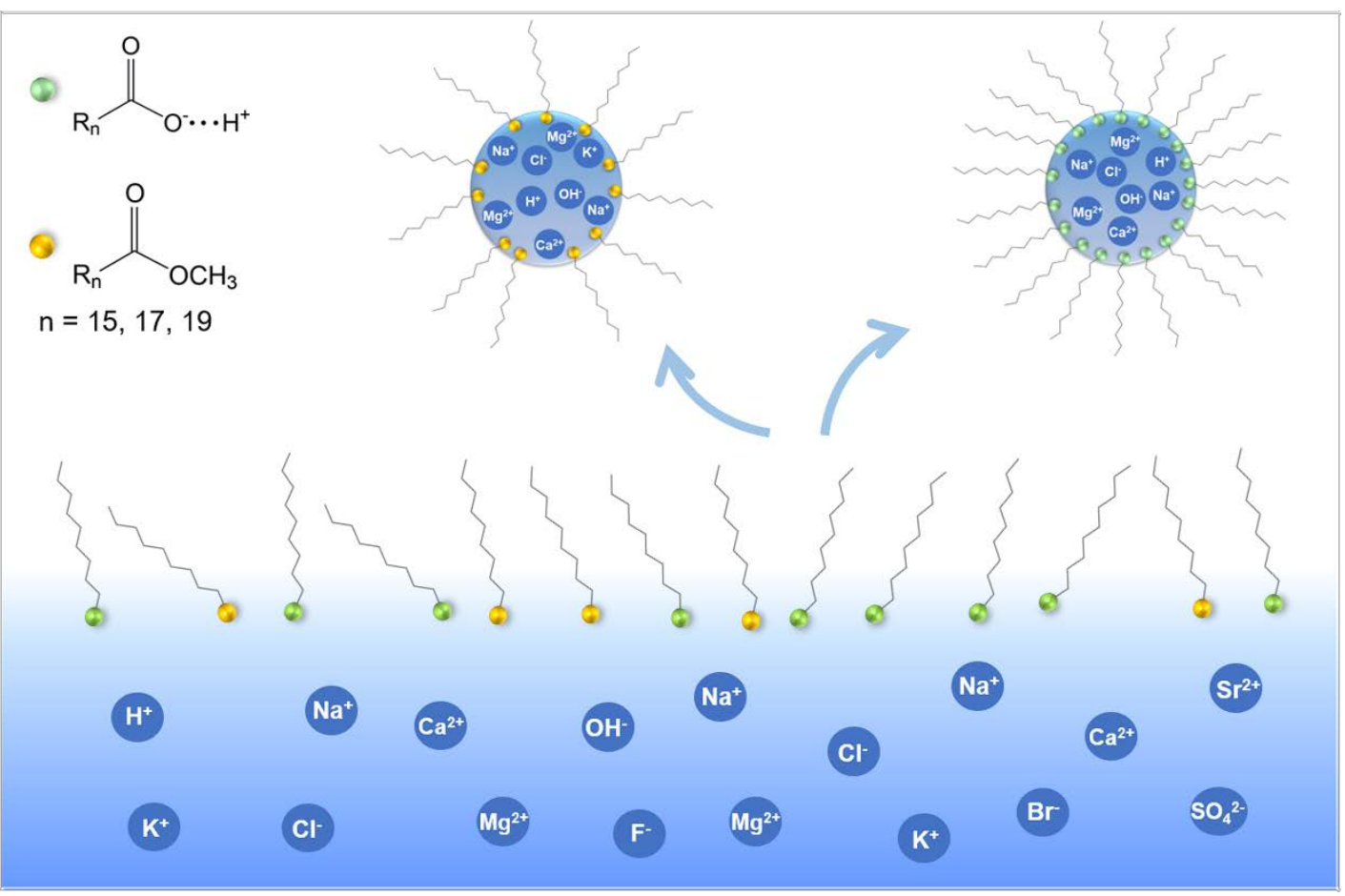




\section{ABSTRACT}

The structure of sea spray aerosols (SSAs) has been described as a saline core coated by organic surfactants. The presence of surface-active compounds at the air-water interface can have a large impact on physical, chemical and optical properties of SSAs. The surfactant molecules chosen for this study, palmitic acid (PA), stearic acid (SA), arachidic acid (AA), methyl palmitate (MP), methyl stearate (MS) and methyl arachidate (MA), were used to investigate the effect of alkyl chain-length, head-groups and sea salts on the surface properties of these monolayers. A Langmuir trough was used for measuring surface pressure-area $(\pi-\mathrm{A})$ isotherms to reveal macroscopic phase behavior of the surface films at the air-water interface. Infrared reflection absorption spectroscopy (IRRAS) was employed to have a molecular-level understanding of the interfacial molecular organization. The $\pi-\mathrm{A}$ isotherms indicated that sea salts, present in the subphase, exert a strong condensing effect on fatty acid monolayers, while exerting expanding effect on fatty acid methyl ester monolayers, which was confirmed by results from IRRAS experiments. IRRAS further revealed that the alkyl chains were in an all-trans conformation, which can be evidenced by the relatively low $v_{\mathrm{a}}\left(\mathrm{CH}_{2}\right)$ and $v_{\mathrm{s}}\left(\mathrm{CH}_{2}\right)$ stretching frequencies. The conformational order changes in the alkyl chains of different film-forming species $(\mathrm{C} 16<\mathrm{C} 18<\mathrm{C} 20)$ were directly revealed by analyzing the relative intensity of the $v_{\mathrm{a}}\left(\mathrm{CH}_{2}\right)$ and $v_{\mathrm{s}}\left(\mathrm{CH}_{2}\right)$ peaks in the $\mathrm{C}-\mathrm{H}$ stretching region. Thus, all the three factors alter the phase behavior and molecular packing of the monolayers at the air-aqueous interface.

Keywords: Langmuir films; fatty acid; fatty acid methyl ester; sea spray aerosols; sea surface microlayer 


\section{INTRODUCTION}

Based on mass concentration, sea spray aerosol (SSA) is one of the largest sources of primary atmospheric aerosol particles. ${ }^{1-2}$ SSAs formed at the sea surface microlayer through bubble-mediated processes, are commonly composed of a sea salt core coated by a thin organic layer. ${ }^{3-6}$ This organic layer is enriched with various organic species from both biological and anthropogenic sources, among which, surface-active species account for a significant portion. ${ }^{5,7}$ Moreover, surface-active species in the sea surface microlayer are expected to be more efficiently transferred into SSA, thus exhibiting much higher concentration than that measured in the sea surface microlayer. ${ }^{7-9}$ Organic films present in SSAs are reported to have inverse micelle structures with the hydrophilic head-groups toward the aqueous phase and the hydrophobic tails to the air. ${ }^{10-11}$ The morphology and conformation of organic films will affect aerosol growth and volatility, ${ }^{12}$ radiative absorption and scattering, ${ }^{6,13}$ reactivity with atmospheric gases, ${ }^{10}$ and cloud condensation nuclei activity. ${ }^{3,8,14-15}$ Thus, understanding the surface characteristics of surfactant molecules is important in atmospheric chemistry because of their significant influence in physical, chemical and optical properties of SSAs. ${ }^{10,16}$

Previous measurements suggested that fatty acids make up a large fraction of the organic materials residing at the interface of marine aerosols. ${ }^{4,7,17}$ Fatty acids present in sea surface microlayer are released primarily during the lysis of phospholipid cellular membranes of marine organisms. ${ }^{11,14}$ Saturated fatty acids, particularly palmitic acid (PA) and stearic acid (SA), contribute significantly to the organic coating of sea salt particles, ${ }^{11,18-19}$ with arachidic acid (AA) showing a relatively lower abundance. $^{20}$ On the other hand, a former analysis of marine aerosols collected over the Mediterranean Sea using a five-stage cascade impactor, found the existence of fatty acid methyl esters from C14 to C34 in SSAs, among which, methyl palmitate (MP) and methyl stearate (MS) were found to be predominant. ${ }^{21-22}$ Natural sources of these fatty acid methyl esters from hydrolysis of various biosynthesized esters such as triglycerides, glycolipids, phospholipids, or waxes, have been reported. ${ }^{21}$ Degradation of particulate material suspended in seawater from marine organisms has been found to be the source of saturated and unsaturated fatty acid methyl esters. ${ }^{23}$

Investigation of the surface properties of these organics at the air-water interface can provide a better understanding of the chemical and physical processes taking place at the surfaces of SSAs in the atmosphere. The film-forming species selected for this research are long chain fatty acids and fatty acid methyl esters with alkyl chain-lengths of C16, C18 and C20. Langmuir trough has been extensively used in atmospheric chemistry to understand the properties of surfaces and surfactant molecules at the interface of aqueous aerosols. ${ }^{10,16}$ Surface pressure-area $(\pi-A)$ isotherms of 
Langmuir monolayers on aqueous surfaces are capable of revealing the underlying phase information of the monolayers being subject to constant compression. However, to gain molecular-level insights into the monolayers, spectroscopic techniques are needed. Infrared reflection absorption spectroscopy (IRRAS) is a helpful technique in studying surface phenomena. Possessing the advantage of being a fast and nondestructive technique, ${ }^{24}$ IRRAS is sensitive to Langmuir monolayers if sufficient scans are taken to obtain spectra with good signal-to-noise ratios. ${ }^{25}$ The application of IRRAS enables us to acquire information about molecular structure, conformation, and orientation of the film-forming species. ${ }^{25-27}$ There are extensive studies elucidating the microscopic profile of Langmuir films of saturated fatty acids at the air-water interface using IRRAS. ${ }^{4,28-30}$ In addition, fatty acid methyl esters are also known to be able to form organized structures at the air-water interface. ${ }^{31-34}$ Previous studies of saturated long chain fatty acid and fatty acid methyl ester monolayers were carried out at the airwater interface with IRRAS technique, by which the conformational order of the monolayers were shown to be increased with increasing alkyl chain-length. ${ }^{35-36}$ The response of SA and AA Langmuir monolayers to atmospheric inorganic ions was explored by Langmuir and IRRAS methods, which confirmed the existence of inorganic ions in the fatty acid monolayers and its impact on the surface properties of aqueous-phase aerosols. ${ }^{15}$ Former investigations were mainly conducted on pure water (PW) or ion-containing subphases. However, properties of sea surface relevant surfactant monolayers on the artificial seawater (ASW) subphase have been rarely studied. ${ }^{37}$ The ASW used in this work is pure water enriched with relevant sea salts, which is more representative of the environment that the surfactant monolayers are exposed to.

In the present study, fatty acid/fatty acid methyl ester-ASW systems were chosen as proxies to further understand the surface properties of marine aerosols. To investigate the influence of sea salts on the studied monolayers, PW was also used as aqueous phase for comparison. Phase behavior and molecular-level features of the fatty acid (PA, SA, AA) and fatty acid methyl ester (MP, MS, MA) monolayers at the air-aqueous interface were examined using $\pi-\mathrm{A}$ isotherms and IRRAS spectra. These compounds commonly have a carboxylic or methyl ester head-group connected to a saturated hydrocarbon chain with different chain-lengths. The objective of the experiments outlined in this paper is to determine the effect of alkyl chain-length, head-groups and sea salts on the properties of the surfactant monolayers at the air-aqueous interface. 


\section{EXPERIMENTAL SECTION}

2.1 Materials. PA ( $\geq 98 \%$, Adamas-beta), SA (98\%, Aladdin), AA (99\%, Aladdin), MP (99\%, Aladdin), MS (99\%, Aladdin) and MA ( $\geq 98 \%$, Aladdin) were used without further purification. These chemicals were dissolved in chloroform to a final concentration of $1 \mathrm{mM}$. Ultrapure water with a resistivity of 18.2 M $\Omega$ was obtained from a Millipore Milli-Q purification system. ASW (see Table 1 for the detailed composition and concentrations) is a ten components mixture with a total concentration of approximately $0.53 \mathrm{M} \cdot{ }^{37-38}$ Specifically, it consists of: $\mathrm{NaCl}$ ( $\geq 99 \%$, Acros Organics), $\mathrm{Na}_{2} \mathrm{SO}_{4}$ (99\%, Alfa Aesar), $\mathrm{KCl}$ (3 M, Alfa Aesar), $\mathrm{NaHCO}_{3}$ ( $\geq 99.7$, Alfa Aesar), $\mathrm{KBr}(\geq 99 \%$, Alfa Aesar), $\mathrm{H}_{3} \mathrm{BO}_{3}$ (99.5\%, Innochem), $\mathrm{NaF}$ ( $\geq 99 \%$, Acros Organics), $\mathrm{MgCl}_{2} \cdot 6 \mathrm{H}_{2} \mathrm{O}$ ( $\geq 99$, Aladdin), $\mathrm{CaCl}_{2} \cdot 2 \mathrm{H}_{2} \mathrm{O}$ (99\%, Adamas-beta), $\mathrm{SrCl}_{2} \cdot 6 \mathrm{H}_{2} \mathrm{O}$ ( $\geq 99$, Alfa Aesar). All these salts were used as received. The $\mathrm{pH}$ of the ASW was measured in the range of $8.0 \pm 0.2$, a value representative of the real seawater. The prepared ASW solution was allowed to equilibrate for several hours before experiments were conducted.

Table 1. Composition of the artificial seawater

\begin{tabular}{lll}
\hline Type of cation & Salt & $\begin{array}{l}\text { Concentration in aqueous solution } \\
(\mathrm{mM})\end{array}$ \\
\hline monovalent & $\mathrm{NaCl}$ & 426 \\
& $\mathrm{Na}_{2} \mathrm{SO}_{4}$ & 29.4 \\
$\mathrm{KCl}$ & 9.45 \\
& $\mathrm{NaHCO}$ & 2.43 \\
& $\mathrm{KBr}$ & 0.857 \\
& $\mathrm{H} 3 \mathrm{BO}_{3}$ & 0.438 \\
& $\mathrm{NaF}$ & 0.0744 \\
\hline divalent & $\mathrm{MgCl}_{2} \cdot 6 \mathrm{H}_{2} \mathrm{O}$ & 55.5 \\
& $\mathrm{CaCl}_{2} \cdot 2 \mathrm{H}_{2} \mathrm{O}$ & 10.8 \\
& $\mathrm{SrCl}_{2} \cdot 6 \mathrm{H}_{2} \mathrm{O}$ & 0.0937 \\
\hline
\end{tabular}

\subsection{Monolayer Spreading and Isotherm Measurements.}

The surface pressure $\pi$ is a measurement of the difference between the surface tension when the surface is covered in a surfactant and the surface tension of the bare surface $\left(\pi=\gamma_{0}-\gamma_{\text {Langmuir, }}\right.$ where $\gamma_{0}$ is the surface tension of pure water and $\gamma_{\text {Langmuir }}$ is the surface tension of water with the Langmuir film at the air-water interface). ${ }^{16,39}$ The surface tension value of ASW was calculated to be in the range of 73.7-74.0 $\mathrm{mN} / \mathrm{m}$ at $291 \pm 1 \mathrm{~K}$ (details are given in the Supporting Information). Standard deviations of the molecular area and surface pressure were $\pm 1 \AA^{2} /$ molecule and $\pm 0.5 \mathrm{mN} / \mathrm{m}$, respectively. 
$\pi-\mathrm{A}$ isotherms of the monolayers at the air-aqueous interface were recorded using a computercontrolled Langmuir trough with two movable barriers sitting on top of the aqueous surface. The trough is made out of Teflon and has inside dimensions of $65 \mathrm{~mm} \times 280 \mathrm{~mm} \times 3 \mathrm{~mm}$. It was placed on a vibration isolation table and closed in a Plexiglas box. At the beginning of the experiments, the two barriers were placed at the ends of the trough. Tens of microliters of chloroform solutions of fatty acids or fatty acid methyl esters were spread dropwise onto PW or ASW subphase using a glass microsyringe. After deposition, about 15 min was allowed before compression to permit the solvent to evaporate and the film to spread spontaneously. A pressure sensor with a Wilhelmy plate made from a piece of rectangular filter paper was used to monitor the surface pressure with high sensitivity. The $\pi-\mathrm{A}$ isotherms were obtained with the pressure sensor while the surface area available for the surfactant molecules was decreased between the barriers. The monolayer at the air-aqueous interface was continuously compressed at a constant rate of $3 \mathrm{~mm} / \mathrm{min}$. All experiments were performed at ambient temperature (291 $\pm 1 \mathrm{~K})$. Each experiment was run at least three times to ensure reproducibility.

2.3 IRRAS Measurements. IRRAS spectra of the monolayers were recorded on a Bruker Vertex 70 FTIR spectrometer equipped with an external variable angle reflectance accessory for monolayer measurements. To have maximum signal strength, the incidence angle of the IR beam was set at $40^{\circ}$ with respect to the surface normal. IRRAS spectra were collected over the range of $4000-400 \mathrm{~cm}^{-1}$ by using a liquid-nitrogen cooled HgCdTe (MCT) detector and averaged for 2000 scans at a resolution of $8 \mathrm{~cm}^{-1}$. For IRRAS spectra collection, the monolayers were continuously compressed to a desired surface pressure from $\sim 0 \mathrm{mN} / \mathrm{m}$. When the barriers were stopped, IRRAS spectra were obtained after a time delay of $60 \mathrm{~s}$, allowed for film equilibrium between trough movement and data collection. IRRAS spectra were obtained at the surface pressure of $28 \mathrm{mN} / \mathrm{m}$, which corresponded to the untilted condensed phase of the $\pi-\mathrm{A}$ isotherms. During the IRRAS data collection, surface pressure changed slightly for the monolayers $(\leq 0.2 \mathrm{mN} / \mathrm{m})$.

\section{RESULTS AND DISCUSSION}

3.1 Surface Pressure-Area Isotherm. $\pi-A$ isotherms provide information about the phase behavior of the monolayers at air-water interfaces. During the movement of the barriers, the phase of the surface monolayer changes with the increase of the surface pressure. The phase changes can thus be recognized from characteristics of the $\pi-\mathrm{A}$ isotherms. The surface pressure monitored as a function 

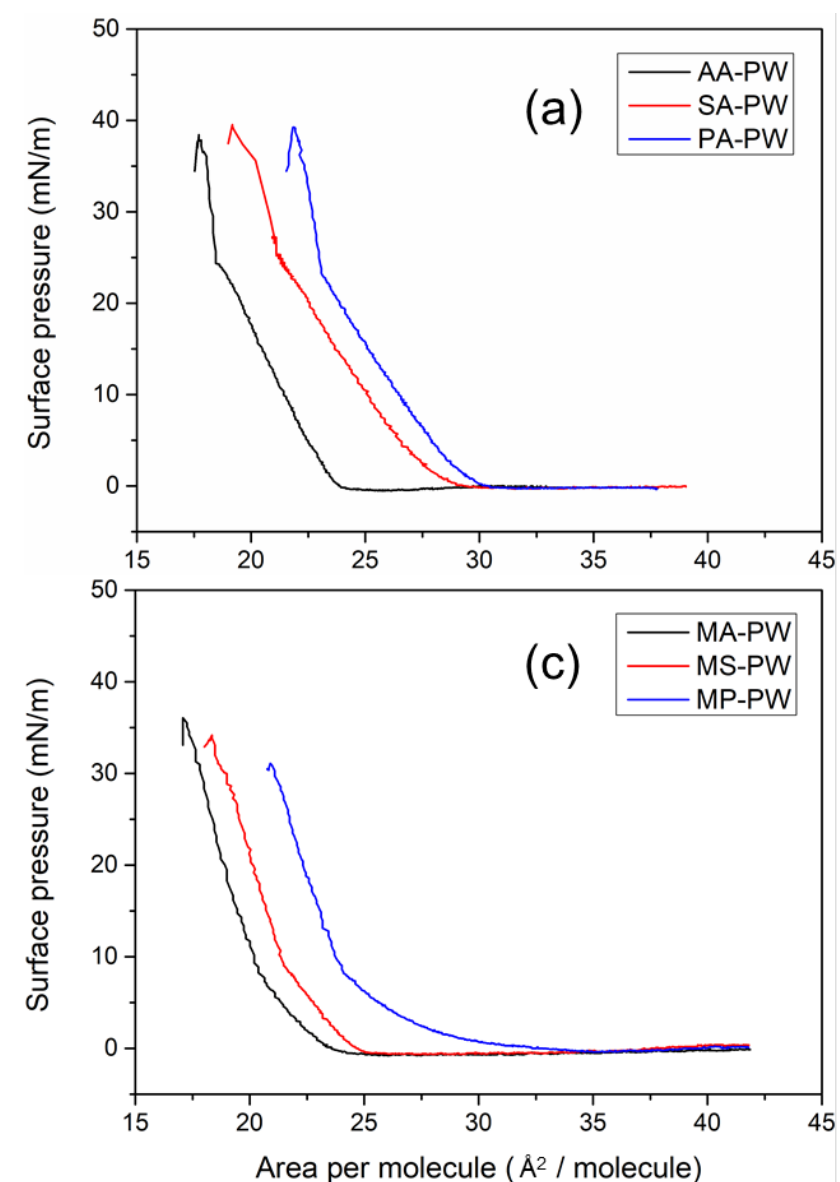
and aqueous subphases.
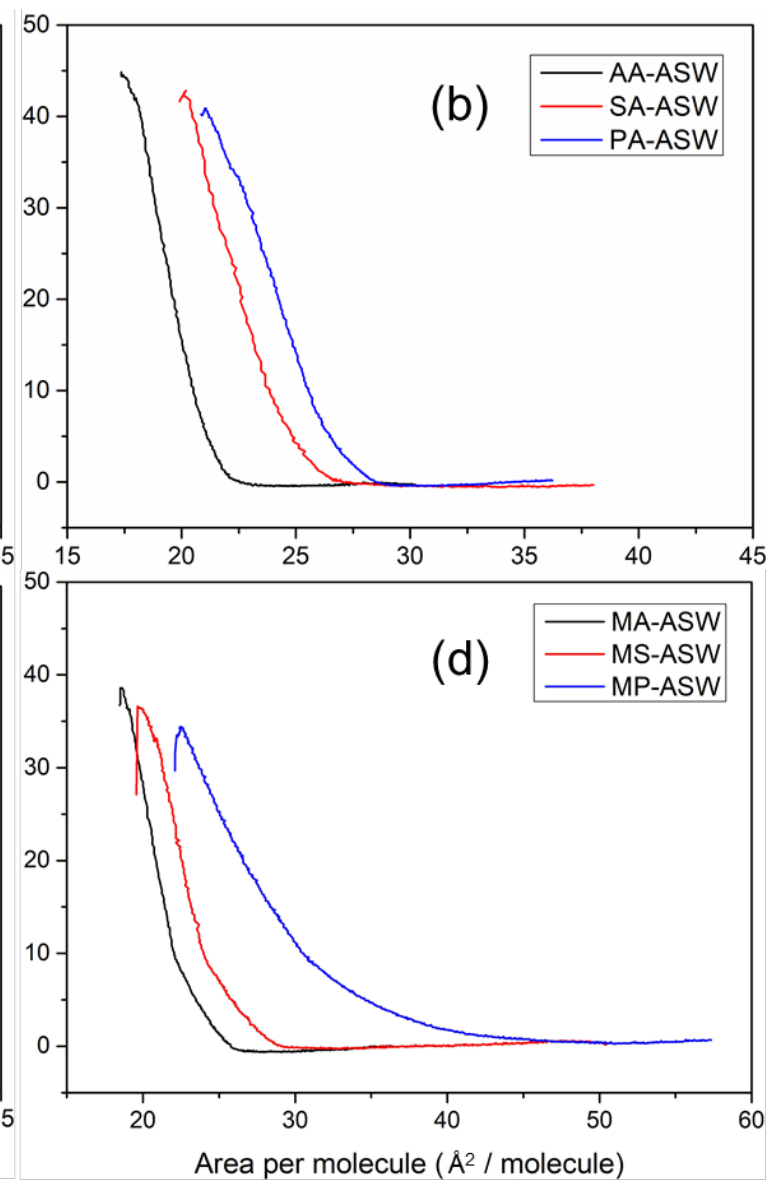

of surface area of fatty acid and fatty acid methyl ester monolayers at room temperature are shown in Figure 1 . These $\pi-\mathrm{A}$ isotherms show remarkable changes along with alkyl chain-length, head-groups,

Figure 1. Surface pressure-area isotherms of fatty acid ((a), (b)) and fatty acid methyl ester ((c), (d)) monolayers on pure water (PW) and artificial sea water (ASW) subphases.

It can be seen from Figure 1(a) that the monolayers of fatty acids on pure water (PW) subphase exhibit the following typical features in $\pi-\mathrm{A}$ isotherms upon compression. At low surface pressure ( $\pi=0 \mathrm{mN} / \mathrm{m}$ ), the fatty acid monolayers show a gaseous-tilted condensed (G-TC) coexistence phase before the lift-off area. In this phase, the alkyl chains are mostly free in space. ${ }^{40}$ And then, the monolayers were enforced into a tilted condensed (TC) phase after subsequent compression. In this phase, there are less spatial movements for the fatty acid molecules. Further compression results in a kink indicates a second-order phase transition from TC to an untilted condensed (UC) phase. In the UC phase the hydrocarbon chains of fatty acids are almost perpendicular to the water subphase. ${ }^{16}$ In 
addition, the surface pressure of second-order phase transitions from TC to UC phase upon compression occur at about $24 \mathrm{mN} / \mathrm{m}$, which is consistent with previous studies. ${ }^{25,41-42}$ Finally, compressing the monolayer even further leads to a collapse state where the monolayer forms threedimensional structures because the surface is no longer stable. ${ }^{16,43-44}$

The $\pi-\mathrm{A}$ isotherms of fatty acids obtained on ASW subphase are presented in Figure 1(b). The isotherm conducted solely with the ASW subphase is shown in Figure S1, from which can be seen that the surface pressure fluctuates around $0 \mathrm{mN} / \mathrm{m}$, indicating that no or negligible surface active substance is present in the ASW subphase. Thus, the influence of organic contaminants present in sea salts can be ruled out. In the presence of sea salts, some changes are found in comparison with the isotherms obtained on the PW subphase. It can be clearly seen that the TC phase disappears, as well as the second-order phase transition. Beyond the lift-off points, the surface pressure increases steeply with a formation of UC phase until the collapse of the monolayers occurs. This is in agreement with a previous report studying the $\pi-\mathrm{A}$ isotherms for PA monolayers formed on $\mathrm{CaCl}_{2}$ solution in. ${ }^{25}$ This behavior was attributed to the condensing effect of metal cations as a result of forming fatty acid salts. ${ }^{25,45}$ Thus, a more orderly packed structure can be speculated for fatty acid monolayers on ASW subphase. The differences in properties of $\pi-A$ isotherms between Figures 1(a) and 1(b) indicate that sea salts present in the subphase alter the macroscopic phase behavior of the long chain fatty acid monolayers.

A strong chain-length dependence of fatty acids is also observed, as the lift-off areas are concerned, which becomes gradually smaller with increasing chain-length. The lift-off areas of the isotherms on PW are 30.3, 29.3 and $24.2 \AA^{2} /$ molecule for PA, SA and AA, respectively. The sequence and general shape of the interfacial isotherms herein are consistent with previous reports. ${ }^{37,46-47}$ The chain-length dependence of lift-off areas indicates that the van der Waals energy increases with the length of chain, and draws the molecules closer as the intermolecular attraction increases. ${ }^{47-48}$ On the other hand, compared to PW, condensation of the fatty acid monolayers occurs when ASW is used as subphase as illustrated in Figure 1(b). It is evident that with ASW as subphase, the lift-off areas are decreased for individual fatty acids. The change in lift-off areas for PA, SA and AA are -1.4, -2.2, $-1.7 \AA^{2} /$ molecule, respectively. Consequently, all the studied fatty acid molecules become more densely packed on ASW than on PW. ${ }^{46}$ At the air-ASW interface, the favorable electrostatic interaction or complexation between fatty acids and sea salts leads to a denser chain packing relative to that of air-PW interface. ${ }^{49}$

Being molecules with saturated single alkyl chains like fatty acids, fatty acid methyl ester 
molecules are fairly compressible as well, and ultimately, can be packed in a highly ordered structure at high surface pressures. As can be seen from Figures 1(c) and 1(d), the slight TC-UC transition occurs at about $8 \mathrm{mN} / \mathrm{m}$ as the surface pressure rises for all the three fatty acid methyl ester monolayers, irrespective of the subphase. Specifically, the $\pi-\mathrm{A}$ isotherm obtained for MP in this study is consistent with a previous research about the temperature dependence of MP monolayers, which found that they are fully condensed below $293 \mathrm{~K}$ and no plateau can be observed in the isotherm. ${ }^{35,50}$ Unlike fatty acid monolayers, the presence of sea salts does not change significantly the shape of fatty acid methyl ester isotherms, although a clear shift to larger mean molecular areas can be observed. Thus, sea salts exert an opposite effect on fatty acid methyl esters compared to fatty acids, resulting in an expansion of the fatty acid methyl ester monolayers. The lift-off areas are clearly observed at about 34.6 and 25.4 and $24.4 \AA^{2} /$ molecule for MP, MS and MA monolayers on PW, respectively. However, when ASW is used as subphase, the values shift to about 45.5, 29.3 and 26.3 $\AA^{2} /$ molecule. Similarly, a former investigation of MP on PW and $\mathrm{NaCl}$ solutions with different ion concentrations (1, 2 and $3 \mathrm{M}$ ), found the expanding effect of $\mathrm{NaCl}$ on the MP monolayer from the increasing lift-off area with increasing $\mathrm{NaCl}$ concentration. ${ }^{50}$ The reason of this behavior was explained to be the increased ionic strength, which influences interactions of the water molecules with the carboxyl group.

To sum up, the presence of sea salts in the subphase has opposite effects on the fatty acid and fatty acid methyl ester monolayers. In addition, similar with fatty acids, the $\pi-\mathrm{A}$ isotherms of fatty acid methyl esters shift to smaller molecular areas with increasing chain-length. Hence, further increase in the hydrocarbon chain-length results in more densely packing of the fatty acid methyl ester molecules. Thus, the conformational order of the alkyl chains increases with increasing chainlength can be concluded from the $\pi-\mathrm{A}$ isotherms: C16 $<$ C18 $<\mathrm{C} 20$, irrespective of head-groups or subphases.

When comparing Figures 1(b) and 1(d), the difference in $\pi-A$ isotherms on ASW subphase indicates that the phase sequence is changed because of the esterification of the carboxyl group, with the appearance of TC phase and second-order phase transitions in fatty acid methyl ester monolayers. When ASW is used as subphase, it can be seen from Figures 1(b) and 1(d) that the lift-off areas of fatty acid methyl esters are much larger than corresponding fatty acids. The main difference between the fatty acids and the fatty acid methyl esters is the head-group structure, where the acids are sensitively influenced by the subphase $\mathrm{pH}$. Empirical evidence suggests that under the conditions of about $\mathrm{pH}=8.2$, the carboxyl group is partially dissociated to be negatively charged. ${ }^{4,25,51}$ It is likely 
that the stability and surface activity of these long chain fatty acids decrease upon dissociation of the carboxylic acid proton. ${ }^{4}$ However, the stability of these monolayers can be greatly improved by electrostatic attractions or complexation with various sea salts in the aqueous subphase. ${ }^{49,52}$ By means of IRRAS, the surface propensity of PA molecules was found to be increased by adding $\mathrm{NaCl}$ into the subphase, ${ }^{4}$ suggesting that deprotonated fatty acids may be found at the air-aqueous interface due to the role of sea salts in surface stabilization. A study of SA monolayers was carried out on 1, 10 and 100 times diluted ASW. ${ }^{37}$ The $\pi-\mathrm{A}$ isotherms of the SA monolayers show an enhanced stability of the film against fracture when the sea salt concentration of the subphase was higher. In case of fatty acid methyl esters, no effect is expected due to ionization of head-groups, because the $\mathrm{pH}$ of the subphase is too low to observe any measurable hydrolysis of the esters. The observed different trends in the isotherms may in part be due to the different interaction mechanisms between the sea salts and the head-groups.

It has been well documented that at low surface pressure, the methyl ester head-group is $E$ configured for expanded fatty acid methyl ester monolayers, where substantial part of the oxo-methyl group is pointing out of the water (Figure S2). The $E$ isomer of fatty acid methyl esters allows the hydration of the polar group and hinders the electrostatic interactions between hydrophilic head-group and cation. However, at higher surface pressure, the head-group is Z-configured with the oxo-methyl component directed into the water for more orderly packed compressed states. ${ }^{35,53}$ In addition, several studies have described the expulsion of water molecules from the monolayer as surface pressure increases. $^{32-33,35}$ When the fatty acid methyl ester monolayers are in Z-configuration, the carbonyl group is shielded by the oxo-methyl component and, thus, the carbonyl group is more or less prevented from being hydrogen-bridged by water molecules. The expelled water from fatty acid methyl ester films could affect the arrangement of $Z$ isomer, allowing the cations to penetrate into the film (Figure S3). In this way, the growth of three-dimensional structures could be favored because the partial charge of the head-group of fatty acid methyl ester would be compensated. ${ }^{33}$ Therefore, we can speculate that the main cause of the instability of the fatty acid methyl ester monolayers in the presence of sea salts is a collapse process which involves the formation of three-dimensional nuclei on the monolayer surface.

The above descriptions suggest that both interactions between adjacent amphiphiles and interactions between amphiphiles and the subphase are important to the macroscopic phase behavior of the monolayers. However, to get deep insights into microscopic molecular arrangement and underlying mechanisms, advanced spectroscopic techniques are necessary. This consideration led us 
to explore the molecular conformation of the monolayer films by means of the IRRAS technique.

3.2 IRRAS Spectra. The monolayers of fatty acids with different chain-lengths (PA, SA, and AA) and corresponding fatty acid methyl esters (MP, MS, MA) on air-aqueous interface were examined using IRRAS. This technique enables us to probe microscopic information such as the conformation order and orientation of the monolayers at the molecular-level. The vibrational modes investigated encompass both head and tail groups of the sample molecules. The stretching vibrations of $\mathrm{C}-\mathrm{H}$ $\left(v\left(\mathrm{CH}_{2}\right)\right)$ at $2820-2950 \mathrm{~cm}^{-1}$, the $v(\mathrm{COO})$ and scissoring band of $\mathrm{C}-\mathrm{H}\left(\delta\left(\mathrm{CH}_{2}\right)\right)$ at $1400-1500 \mathrm{~cm}^{-1}$, and the $v(\mathrm{C}=\mathrm{O})$ at $1700-1800 \mathrm{~cm}^{-1}$ were probed.
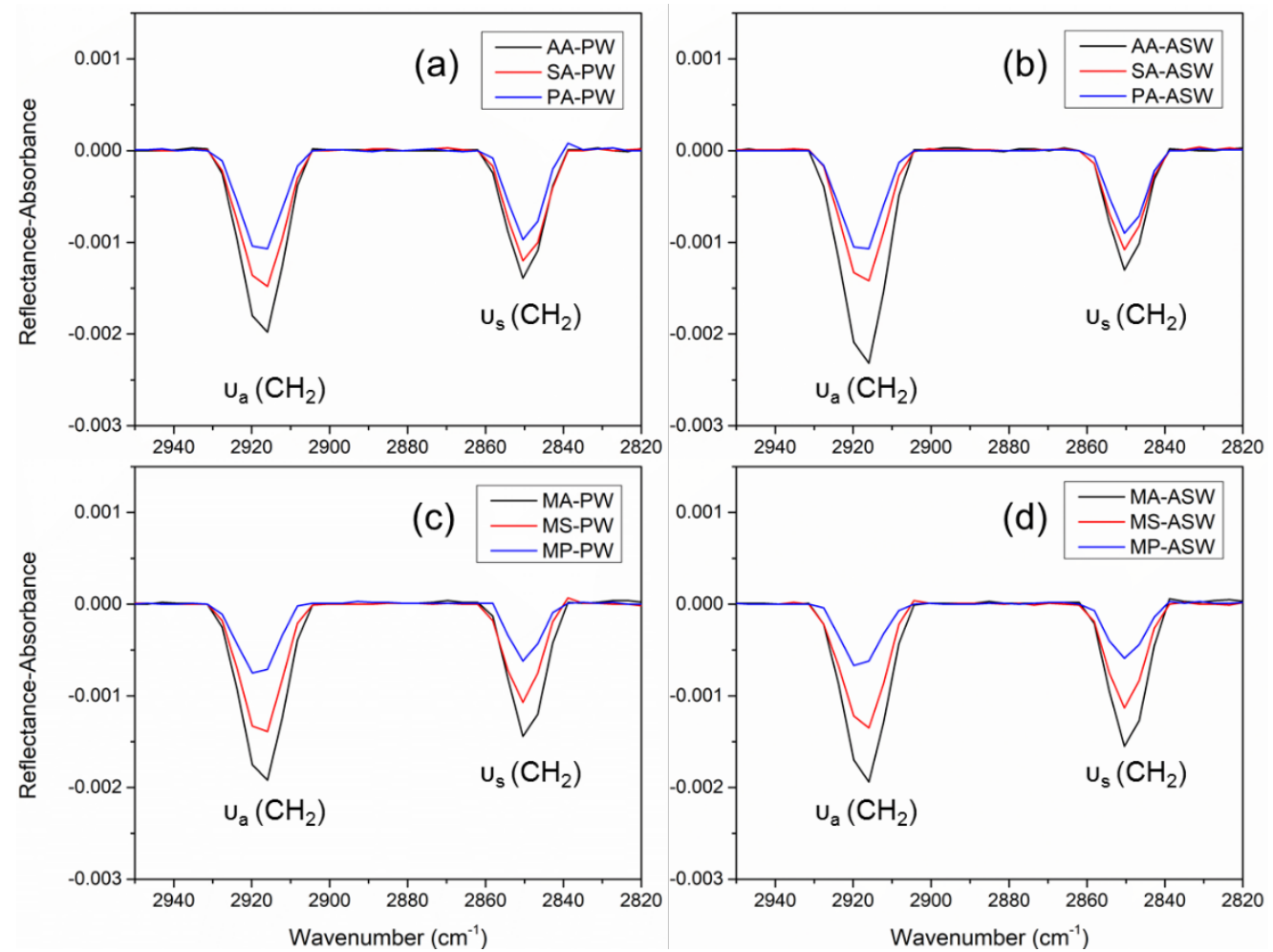

Figure 2. IRRAS spectra (2820-2950 $\left.\mathrm{cm}^{-1}\right)$ of the fatty acid ((a), (b)) and fatty acid methyl ester ((c), (d)) monolayers recorded at $28 \mathrm{mN} / \mathrm{m}$ on pure water (PW) and artificial sea water (ASW) subphases at the incidence angle of $40^{\circ}$.

IRRAS spectra (2820-2950 $\mathrm{cm}^{-1}$ ) of the fatty acid and fatty acid methyl ester monolayers in the UC phase on PW and ASW subphases are shown in Figures 2(a)-(d). In Figure 2(a), for fatty acid monolayers on air-PW interface, the two bands at around $2916 \mathrm{~cm}^{-1}$ and $2850 \mathrm{~cm}^{-1}$ can be assigned to the methylene antisymmetric $\left(v_{\mathrm{a}}\left(\mathrm{CH}_{2}\right)\right)$ and methylene symmetric $\left(v_{\mathrm{s}}\left(\mathrm{CH}_{2}\right)\right)$ stretching vibrations 
of the hydrocarbon chains, respectively. At the incidence angle of $40^{\circ}$, these bands show negative reflection absorbance. The $v_{\mathrm{a}}\left(\mathrm{CH}_{2}\right)$ and $v_{\mathrm{s}}\left(\mathrm{CH}_{2}\right)$ frequencies have been known to be sensitive to the conformation order of hydrocarbon chains. ${ }^{45,54}$ Lower frequencies are characteristic of preferential all-trans conformers in highly ordered chains, while the number of gauche conformers increases with increasing frequency and width of the bands. ${ }^{17,29}$ For all-trans conformations of the fully extended tail chains, the symmetric and asymmetric stretching vibrations of the methylene groups are usually present in the narrow ranges of 2846-2850 and 2915-2918 $\mathrm{cm}^{-1}$, respectively, and in the distinctly different ranges of 2854-2856 and 2924-2928 cm presence of gauche conformations. ${ }^{55}$ The relatively low frequency positions of the $v_{\mathrm{s}}\left(\mathrm{CH}_{2}\right)$ and $v_{\mathrm{a}}\left(\mathrm{CH}_{2}\right)$ stretching modes at about $2850 \mathrm{~cm}^{-1}$ and $2916 \mathrm{~cm}^{-1}$, indicate that the alkyl chains are mostly in highly ordered all-trans conformations. ${ }^{56}$ This shows clearly that the alkyl chains are almost perpendicular to the air-water interface. The all-trans conformation can also be found in other compressed monolayers shown in Figures 2(b), 2(c) and 2(d), irrespective of the head-groups or the subphases. The highly ordered structure of fatty acids directly correlates with the van der Waals interaction between adjacent alkyl chains, the interactions between adjacent $\mathrm{COOH}$ head-groups and those between head-groups and aqueous subphase. An orderly packed structure can maximize interactions with an all-trans conformation between adjacent alkyl chains. ${ }^{25}$ For the fatty acid methyl ester monolayers, the steric demand in the $E$-configuration is very high. This structure results in quite strongly tilted molecules and a poor conformational order. When the monolayer is further compressed, a reduction of the available area forces molecules to approach each other and pack more densely. As a compromise, the methyl group is squeezed into the subphase, thus resulting in a Z-conformation of amphiphiles in the condensed phase. With this conformation, the oxo-methyl group facilitates the alltrans configuration of the alkyl chains. Consequently, the head-group can be forced into the Zconfiguration with increasing surface pressure and result in the all-trans conformation of the alkyl chains. ${ }^{35}$

All the fatty acids and corresponding methyl esters commonly possess saturated hydrocarbon chains with different chain-lengths. IRRAS bands arising from these alkyl chains provide the clear spectra and hence reliable information about molecular conformation in the monolayers. ${ }^{30}$ The peak heights and areas of the $v_{\mathrm{a}}\left(\mathrm{CH}_{2}\right)$ and $v_{\mathrm{s}}\left(\mathrm{CH}_{2}\right)$ bands indicate the packing density of the alkyl chains. ${ }^{35}$ It can be evidenced from Figure 2 that the peak heights and areas for the methylene stretching vibrations increase with increasing chain-length, irrespective of head-groups or subphases. As the directions of $v_{\mathrm{a}}\left(\mathrm{CH}_{2}\right)$ and $v_{\mathrm{s}}\left(\mathrm{CH}_{2}\right)$ vibrational modes are orthogonal to the molecular axis, strong 
intensities of the bands indicate that the molecule stands nearly perpendicular to the water subphase when the hydrocarbon chain is in the all-trans conformation. ${ }^{57}$ Hence, the much smaller peak intensity of C16 relative to the higher homologues is indicative of a substantially stronger tilt and less ordered conformation of the molecules, reflecting more orderly packed structure of higher homologues at the UC state. It is necessary to consider these data in relation to the $\pi-\mathrm{A}$ isotherms of Figure 1, which shows that smaller areas were occupied by monolayers formed by surfactants with longer alkyl chain-length.

Table 2. The peak-height intensity ratio between the antisymmetric and symmetric bands of the $\mathrm{CH}_{2}$ groups $\left(I_{\mathrm{as}} / I_{\mathrm{s}}\right)$ for the fatty acid and fatty acid methyl ester monolayers on pure water (PW) and artificial sea water (ASW) subphases.

\begin{tabular}{ccccccc}
\hline subphase & PA & SA & AA & MP & MS & MA \\
\hline PW & 1.10 & 1.23 & 1.43 & 1.21 & 1.29 & 1.33 \\
ASW & 1.19 & 1.32 & 1.78 & 1.14 & 1.19 & 1.26 \\
\hline
\end{tabular}

The conformational order changes in the alkyl chains introduced by sea salts, head-groups or alkyl chain-length can be further revealed by analyzing the relative intensity of the $v_{\mathrm{a}}\left(\mathrm{CH}_{2}\right)$ and the $v_{\mathrm{s}}\left(\mathrm{CH}_{2}\right)$ peaks in the $\mathrm{C}-\mathrm{H}$ stretching region. ${ }^{15}$ The peak-height intensity ratios between the antisymmetric and symmetric bands of the $\mathrm{CH}_{2}$ groups $\left(I_{\mathrm{as}} / I_{\mathrm{s}}\right)$ for the studied monolayers are presented in Table 2 for direct comparison. In Figure 2, the intensities of $v_{\mathrm{s}}\left(\mathrm{CH}_{2}\right)$ peaks are relatively weaker than those of the $v_{\mathrm{a}}\left(\mathrm{CH}_{2}\right)$ peaks, thus giving $I_{\mathrm{as}} / I_{\mathrm{s}}$ values greater than one. Qualitatively speaking, larger $I_{\mathrm{as}} / I_{\mathrm{s}}$ ratio indicates more orderly packed alkyl chains with nearly all-trans conformation. ${ }^{58-60}$ It can be seen from Table 2 that the ratio values are smaller for monolayers formed by molecules with shorter alkyl chain-length, irrespective of head-groups or subphases, indicating the existence of gauche defects in corresponding monolayers. Therefore, the pronounced chain order increase with increasing chain-length can be concluded from IRRAS spectra: C16 < C18 < C20, which is in line with the conclusion obtained from the $\pi-\mathrm{A}$ isotherms (Figure 1). As was shown in the $\pi-\mathrm{A}$ isotherms, sea salts demonstrate a condensing effect on the fatty acid monolayers, which consequently leads to the absence of the TC phase. The IRRAS spectra obtained on the ASW surface confirm this effect, as can be seen from the larger intensity ratios of the $v_{\mathrm{a}}\left(\mathrm{CH}_{2}\right)$ over the $v_{\mathrm{s}}\left(\mathrm{CH}_{2}\right)$ than those on the PW subphase in individual spectra, with values of $I_{\mathrm{as}} / I_{\mathrm{s}}$ increasing from 1.10, 1.23 and 1.43 to $1.19,1.32$ and 1.78 , respectively. This result can be attributed to the decrease in the 
concentration of gauche defects and tilt angle of monolayers formed on ASW subphase. With respect 350 to fatty acid methyl esters, the intensity ratios of $I_{\mathrm{as}} / I_{\mathrm{s}}$ obtained on ASW (1.14, 1.19 and 1.26) surface 351 are smaller than those on PW (1.21, 1.29 and 1.33), which indicates that the fatty acid methyl ester monolayers are disordered by sea salts. This can be evidenced by the expanding effect introduced by sea salts on fatty acid methyl ester monolayers. Therefore, IRRAS experiments confirm the contrary effects of sea salts on fatty acid and fatty acid methyl ester monolayers as can be observed from $\pi-\mathrm{A}$ isotherms.

Evidences of monolayer orientation and structural changes along with alkyl chain-length, headgroups, and subphases are provided mainly by details of the $v_{\mathrm{a}}\left(\mathrm{CH}_{2}\right)$ and the $v_{\mathrm{s}}\left(\mathrm{CH}_{2}\right)$ bands. Peak position, height, area and intensity ratios were utilized to support the analysis. These characteristics correlate well with those shown by the $\pi-\mathrm{A}$ isotherms. Information about the dependence of the chain order on the alkyl chain-length and subphases, i.e., the overall effect of an increase in alkyl chainlength leading to an increase in order, ASW acts to condense fatty acid films and expand fatty acid methyl ester films, was inferred from both the IRRAS spectra and the $\pi-\mathrm{A}$ isotherms. The IRRAS technique not only allows for the characterization of all the above chain conformation and orientation details, but also provides valuable information about molecular interaction between the monolayers and the aqueous subphase.
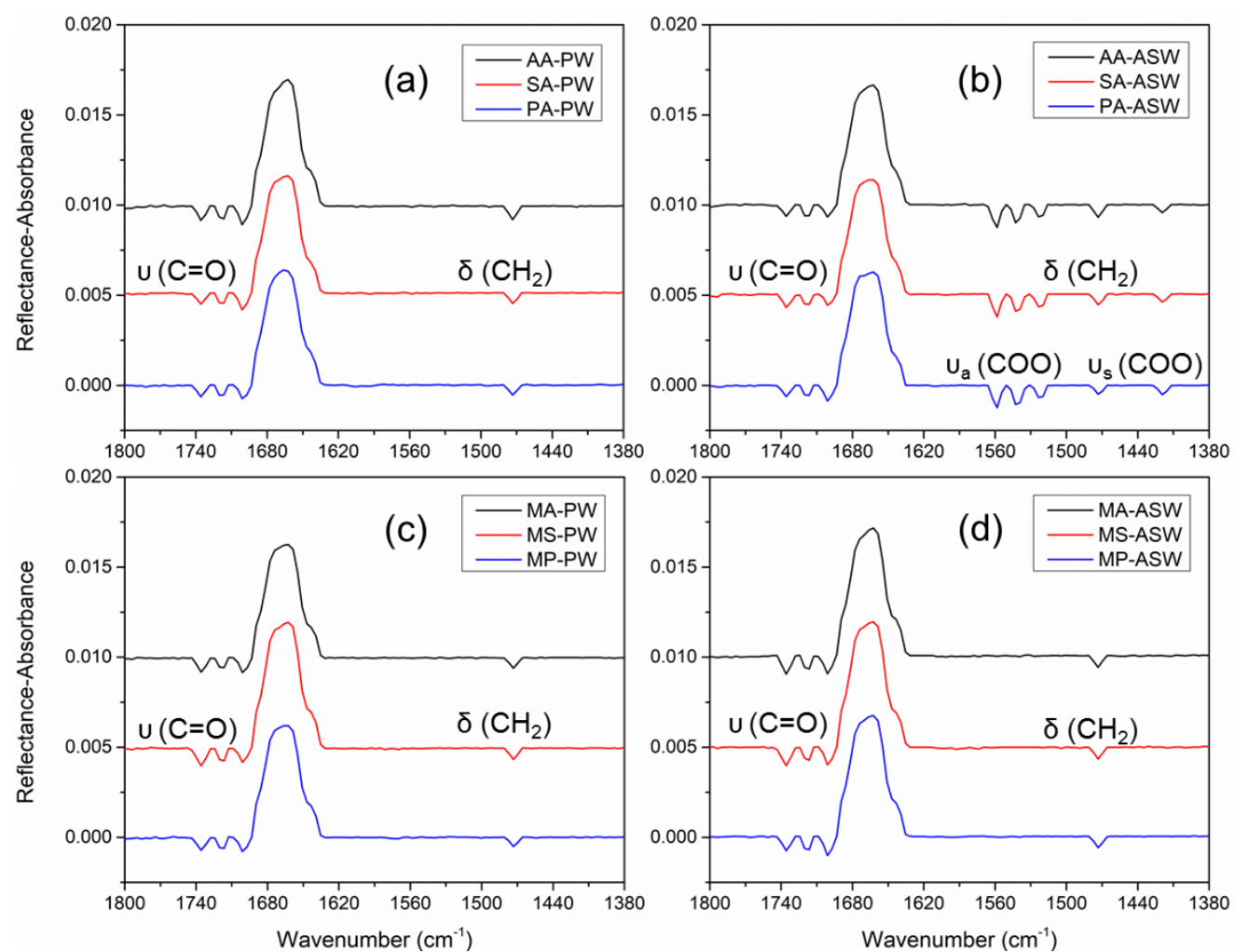
Figure 3. IRRAS spectra (1380-1800 $\left.\mathrm{cm}^{-1}\right)$ of the fatty acid ((a), (b)) and fatty acid methyl ester ((c), (d)) monolayers recorded at $28 \mathrm{mN} / \mathrm{m}$ on pure water (PW) and artificial sea water (ASW) at the incidence angle of $40^{\circ}$.

Figure 3 shows IRRAS spectra $\left(1800-1380 \mathrm{~cm}^{-1}\right)$ of the $v(\mathrm{C}=\mathrm{O}), \delta\left(\mathrm{CH}_{2}\right)$ and $v(\mathrm{COO})$ regions of the fatty acid and fatty acid methyl ester monolayers in the UC phase on the PW and ASW subphases. Three peaks are observed at 1739, 1720, and $1704 \mathrm{~cm}^{-1}$, which can be attributed to the stretching vibrations of the free $\mathrm{C}=\mathrm{O}$ group, the $\mathrm{C}=\mathrm{O}$ group involved in one and two hydrogen bonds, respectively. A previous IRRAS investigation of SA monolayer at the air-water interface gave similar results. ${ }^{36}$ The ability of the carbonyl group to form hydrogen bonds was explained to be a mixture effect of hydration by the water subphase and by side-bridging hydrogen-bond formation between adjacent fatty acid molecules. ${ }^{36,61}$ The sharp singlet observed at $1472 \mathrm{~cm}^{-1}$ is ascribed to the $\delta\left(\mathrm{CH}_{2}\right)$ band of the methylene groups. ${ }^{29,54}$

IRRAS spectra of fatty acids on the ASW subphase (Figure 3 (b)) in the region of COO stretching vibrations can provide insights into interaction mechanisms between carboxylic acid headgroups and the subphase. In the presence of sea salts, additional peaks arising from the asymmetric $\left(v_{\mathrm{a}}(\mathrm{COO})\right.$ and symmetric $\left(v_{\mathrm{s}}(\mathrm{COO})\right)$ stretching modes of the $\mathrm{COO}$ group are observed. The three peaks including 1558, 1542, $1523 \mathrm{~cm}^{-1}$ are resulted from the splitting of the $v_{\mathrm{a}}(\mathrm{COO})$ stretching vibration, ${ }^{15}$ while the peak at $1419 \mathrm{~cm}^{-1}$ is assigned to the $v_{\mathrm{s}}(\mathrm{COO})$ stretching mode. ${ }^{38}$ Complexation of ions to surface-active species has been known to alter their orientation, packing, and surface morphology. ${ }^{17,62}$ The stability of the SA monolayer was found to be increased significantly at high $\mathrm{pH}$ values due to ionization of the surfactant by $\mathrm{Ca}^{2+}$ and $\mathrm{Mg}^{2+}$ in the subphase. ${ }^{63}$ It has been reported that metal cations can bind to the carboxylate group in several ways including ionic binding, unidentate type, bidentate chelate type and bidentate bridging type. ${ }^{24}$ The bonding type of metal cations to the carboxylate group in the UC state can be classified by the difference between the antisymmetric and symmetric COO stretching frequencies. In this work, the differences in $v_{\mathrm{a}}(\mathrm{COO})$ and $v_{\mathrm{s}}(\mathrm{COO})$ stretching frequencies give three values of about 139, 123 and $104 \mathrm{~cm}^{-1}$, respectively. The difference in $v_{\mathrm{a}}(\mathrm{COO})$ and $v_{\mathrm{s}}(\mathrm{COO})$ stretching frequencies for dissociated acid was estimated to be $138 \mathrm{~cm}^{-1} .{ }^{24}$ Typically, the values for bidentate bridging coordination are somewhat close to that for a dissociated carboxylate ion, and values of bidentate chelate coordination are less than that of a dissociated carboxylate ion. ${ }^{24}$ Thus, the main component at $1558 \mathrm{~cm}^{-1}$ belongs to a bidentate bridging 
structure, while the components at $1542 \mathrm{~cm}^{-1}$ and $1523 \mathrm{~cm}^{-1}$ can be attributed to bidentate chelate coordinations. Hence, in the presence of the ASW subphase, dissociated fatty acids form bidentate bridged and bidentate chelate coordinations. As the ASW used herein is a complex mixture of sea salts, it is hard to distinguish which cation the fatty acids are binding to. In this regard, sea salts are treated as a whole to consider their interaction with the head-groups of fatty acid and fatty acid methyl ester molecules.

3.3 Atmospheric Implications. The organic films that reside at the air-water interface exert a significant impact on many properties of SSAs, such as its ability to exchange species including water molecules and traces gases across the interface, ${ }^{64}$ its ability to absorb or scatter radiation, ${ }^{6,10,13}$ and its reactivity towards oxidative gases. ${ }^{65}$ Long chain fatty acid and fatty acid methyl ester monolayers at the air-aqueous interface were utilized as simplified model of organic-coated SSAs. The impact of sea salts, head-groups and alkyl chain-length on phase behavior and molecular organization of the monolayer films was fully characterized. The higher stability of monolayers formed by species with longer alkyl chain-length is clear. The lifetime of the hydrophobic layer on SSA is dependent on many variables, an important one being the carbon chain-length of the surfactants comprising the coating. ${ }^{65-}$ ${ }^{66}$ Properties of the aqueous core, including $\mathrm{pH}$ and composition, also affect the stability of the organic surface films. Adding sea salts into the subphase improves the stability of the fatty acid films by binding to the carboxylic acid groups through bidentate bridged and bidentate chelate coordinations. Thus, deprotonated fatty acids may be found at the air-aqueous interface of aerosol particles partly due to the role of sea salts in surface stabilization.

ASW caused condensation of the fatty acid surface films, leading to tightly packed molecules. However, the expansion effect was introduced by ASW toward fatty acid methyl ester films, which led to loosely packed molecules. Thus, we can speculate that fatty acid molecules reside at the interface of SSAs with greater stability and higher packing density relative to fatty acid methyl esters. This is in line with field measurements of marine aerosols utilizing time-of-flight secondary ion mass spectrometry (TOF-SIMS) as a surface sensitive analysis technique. The aerosols collected in the field exhibited surface layers dominated by fatty acids. ${ }^{67}$ One major effect of surface active organic monolayer shown both by observations and modeling, is the lowering of the particle surface tension. ${ }^{39,68}$ Surface active species present at the air-water interface have the potential to lower the surface tension of a growing droplet relative to pure water at a given relative humidity. ${ }^{69}$ A lower surface tension promotes small particle growth at lower relative humidity in accord with the Kelvin 
effect $^{69-70}$ and increasing particle cloud condensation nuclei activation efficiency, ${ }^{39,68}$ thereby causing the droplets to grow larger than predicted. As can be seen from the surface pressure-area isotherms, beyond the lift-off points, the surface pressure of the interface increases with decreasing mean molecular areas, indicating the reduction of surface tension. The surface tension of ASW interface covered by fatty acid reduces more rapidly along with deceasing mean molecular areas than in corresponding methyl ester. Thus the effectiveness of the film on surface tension reduction will depend on the species of film-forming molecules as well as chemical composition of the aqueous core. In addition, the optical properties of aerosols are largely dependent upon their size and in this regard, the alteration in aerosol size will affect their scattering efficiency. ${ }^{46}$

\section{CONCLUSIONS}

In this work, monolayers of long chain fatty acids and fatty acid methyl esters (C16, C18, C20) at the air-aqueous interface were used as proxies for the organic-coated SSAs. Both $\pi-\mathrm{A}$ isotherms and IRRAS spectra were applied to systematically investigate the effect of alkyl chain-length, headgroups and sea salts on the surface properties of organic monolayers. It was shown by $\pi-\mathrm{A}$ isotherms that sea salts have a condensing effect on fatty acid monolayers, meanwhile, obvious differences in phase behavior were detected over the PW and ASW subphases. However, an expansion effect of sea salts on fatty acid methyl ester monolayers was observed, without any distinct change of the phase transitions between $\pi-\mathrm{A}$ isotherms detected over the PW and ASW subphases. The pronounced chain order increase with increasing chain-length $(\mathrm{C} 16<\mathrm{C} 18<\mathrm{C} 20)$ was revealed by $\pi-\mathrm{A}$ isotherms, irrespective of head-groups or subphases. These findings were further confirmed by IRRAS spectra. Substantial intensity ratio increases in the $I_{\mathrm{as}} / I_{\mathrm{s}}$ were observed on monolayers formed by species with longer chain-length. From the differences between $v_{\mathrm{a}}(\mathrm{COO})$ and $v_{\mathrm{s}}(\mathrm{COO})$ stretching frequencies, the dominant binding coordinations between deprotonated fatty acids and sea salts were found to be bidentate bridging and bidentate chelate. These results indicate that the surface characteristics of organic-coated SSAs are influenced by both the chemical composition of the aqueous core and species of film-forming molecules.

\section{ASSOCIATED CONTENT}

\section{Supporting Information}

Calculation of surface tension of artificial seawater, surface pressure-area isotherms of artificial seawater and isotherm of steric acid monolayer on artificial seawater subphase (Figure S1), schematic 
representation of $E$ - and Z-conformation of fatty acid methyl esters at the air-water interface (Figure S2), and schematic representation of fatty acid methyl ester monolayers at the air-seawater interface (Figure S3).

\section{AUTHOR INFORMATION}

\section{Corresponding Author}

*Email: lindu@sdu.edu.cn, Tel: +86-532-58631980

\section{Notes}

There are no conflicts of interest to declare.

\section{ACKNOWLEDGMENTS}

This work was supported by National Natural Science Foundation of China (91644214, 21876098), Shandong Natural Science Fund for Distinguished Young Scholars (JQ201705) and the the Marie Curie International Research Staff Exchange project MARSU (Grant 690958).

\section{REFERENCE}

(1) Braun, R. A.; Dadashazar, H.; MacDonald, A. B.; Aldhaif, A. M.; Maudlin, L. C.; Crosbie, E.; Aghdam, M. A.; Mardi, A. H.; Sorooshian, A. Impact of wildfire emissions on chloride and bromide depletion in marine aerosol particles. Environ. Sci. Technol. 2017, 51 (16), 9013-9021.

(2) Quinn, P. K.; Coffman, D. J.; Johnson, J. E.; Upchurch, L. M.; Bates, T. S. Small fraction of marine cloud condensation nuclei made up of sea spray aerosol. Nat. Geosci. 2017, 10 (9), 674-679. (3) Jayarathne, T.; Sultana, C. M.; Lee, C.; Malfatti, F.; Cox, J. L.; Pendergraft, M. A.; Moore, K. A.; Azam, F.; Tivanski, A. V.; Cappa, C. D.; Bertram, T. H.; Grassian, V. H.; Prather, K. A.; Stone, E. A. Enrichment of saccharides and divalent cations in sea spray aerosol during two phytoplankton blooms. Environ. Sci. Technol. 2016, 50 (21), 11511-11520.

(4) Adams, E. M.; Wellen, B. A.; Thiraux, R.; Reddy, S. K.; Vidalis, A. S.; Paesani, F.; Allen, H. C. Sodium-carboxylate contact ion pair formation induces stabilization of palmitic acid monolayers at high pH. Phys. Chem. Chem. Phys. 2017, 19 (16), 10481-10490.

(5) Tseng, R. S.; Viechnicki, J. T.; Skop, R. A.; Brown, J. W. Sea-to-air transfer of surface-active organic-compounds by bursting bubbles. J. Geophys. Res.: Oceans 1992, 97 (C4), 5201-5206.

(6) Tervahattu, H.; Hartonen, K.; Kerminen, V. M.; Kupiainen, K.; Aamio, P.; Koskentalo, T.; Tuck, A. F.; Vaida, V. New evidence of an organic layer on marine aerosols. J. Geophys. Res. 2002, 107 (D7-D8), AAC1-AAC9.

(7) Cochran, R. E.; Laskina, O.; Jayarathne, T.; Laskin, A.; Laskin, J.; Lin, P.; Sultana, C.; Lee, C.; Moore, K. A.; Cappa, C. D. Analysis of organic anionic surfactants in fine and coarse fractions of freshly emitted sea spray aerosol. Environ. Sci. Technol. 2016, 50 (5), 2477-2486.

(8) Lin, W.; Clark, A. J.; Paesani, F. Effects of surface pressure on the properties of Langmuir monolayers and interfacial water at the air-water interface. Langmuir 2015, 31 (7), 2147-2156.

(9) Tervahattu, H.; Hartonen, K.; Kerminen, V. M.; Kupiainen, K.; Aarnio, P.; Koskentalo, T.; Tuck, A. F.; Vaida, V. New evidence of an organic layer on marine aerosols. J. Geophys. Res.: Atmos. 2002, 107 (D7), 4053. 
(10) Donaldson, D. J.; Vaida, V. The influence of organic films at the air-aqueous boundary on atmospheric processes. Chem. Rev. 2006, 106 (4), 1445-1461.

(11) Ellison, G. B.; Tuck, A. F.; Vaida, V. Atmospheric processing of organic aerosols. J. Geophys. Res.: Atmos. 1999, 104 (D9), 11633-11641.

(12) Feingold, G.; Chuang, P. Y. Analysis of the influence of film-forming compounds on droplet growth: Implications for cloud microphysical processes and climate. J. Atmos. Sci. 2002, 59 (12), 2006-2018.

(13) Vaida, V. Atmospheric radical chemistry revisited Sunlight may directly drive previously unknown organic reactions at environmental surfaces. Science 2016, 353 (6300), 650-650.

(14) Zhang, T.; Cathcart, M. G.; Vidalis, A. S.; Allen, H. C. Cation effects on phosphatidic acid monolayers at various pH conditions. Chem. Phys. Lipids 2016, 200, 24-31.

(15) Li, S. Y.; Du, L.; Wei, Z. M.; Wang, W. X. Aqueous-phase aerosols on the air-water interface: Response of fatty acid Langmuir monolayers to atmospheric inorganic ions. Sci. Total Environ. 2017, 580, 1155-1161.

(16) Larsen, M. C. Binary phase diagrams at the air-water interface: An experiment for undergraduate physical chemistry students. J. Chem. Educ. 2014, 91 (4), 597-601.

(17) Adams, E. M.; Casper, C. B.; Allen, H. C. Effect of cation enrichment on dipalmitoylphosphatidylcholine (DPPC) monolayers at the air-water interface. J. Colloid Interface Sci. 2016, 478, 353-364.

(18) Rouviere, A.; Ammann, M. The effect of fatty acid surfactants on the uptake of ozone to aqueous halogenide particles. Atmos. Chem. Phys. 2010, 10 (23), 11489-11500.

(19) Shrestha, M.; Luo, M.; Li, Y.; Xiang, B.; Xiong, W.; Grassian, V. H. Let there be light: stability of palmitic acid monolayers at the air/salt water interface in the presence and absence of simulated solar light and a photosensitizer. Chem. Sci. 2018, 9 (26), 5716-5723.

(20) Mochida, M.; Kitamori, Y.; Kawamura, K.; Nojiri, Y.; Suzuki, K. Fatty acids in the marine atmosphere: Factors governing their concentrations and evaluation of organic films on sea-salt particles. J. Geophys. Res.: Atmos. 2002, 107 (D17), 4325.

(21) Sicre, M. A.; Marty, J. C.; Saliot, A. n-Alkanes, fatty acid esters, and fatty acid salts in size fractionated aerosols collected over the Mediterranean Sea. J. Geophys. Res.: Atmos. 1990, 95 (D4), 3649-3657.

(22) Cincinelli, A.; Stortini, A.; Perugini, M.; Checchini, L.; Lepri, L. Organic pollutants in seasurface microlayer and aerosol in the coastal environment of Leghorn-(Tyrrhenian Sea). Mar. Chem. 2001, 76 (1-2), 77-98.

(23) Ehrhardt, M.; Osterroht, C.; Petrick, G. Fatty-acid methyl esters dissolved in seawater and associated with suspended particulate material. Mar. Chem. 1980, 10 (1), 67-76.

(24) Mukherjee, S.; Datta, A. Langmuir-Blodgett deposition selects carboxylate headgroup coordination. Phys. Rev. E 2011, 84 (4), 041601.

(25) Tang, C. Y.; Huang, Z. S. A.; Allen, H. C. Binding of $\mathrm{Mg}^{2+}$ and $\mathrm{Ca}^{2+}$ to palmitic acid and deprotonation of the $\mathrm{COOH}$ headgroup studied by vibrational sum frequency generation spectroscopy. J. Phys. Chem. B 2010, 114 (51), 17068-17076.

(26) Gericke, A.; Brauner, J. W.; Erukulla, R. K.; Bittman, R.; Mendelsohn, R. In-situ investigation of partially deuterated fatty acid and phospholipid monolayers at the air-water interface by IR reflection-absorption spectroscopy. Thin Solid Films 1996, 284 (1-2), 428-431.

(27) Tang, C. Y.; Allen, H. C. Ionic binding of $\mathrm{Na}^{+}$versus $\mathrm{K}^{+}$to the carboxylic acid headgroup of palmitic acid monolayers studied by vibrational sum frequency generation spectroscopy. J. Phys. Chem. A 2009, 113 (26), 7383-7393. 
(28) Teer, E.; Knobler, C. M.; Lautz, C.; Wurlitzer, S.; Kildae, J.; Fischer, T. M. Optical measurements of the phase diagrams of Langmuir monolayers of fatty acid, ester, and alcohol mixtures by brewster-angle microscopy. J. Chem. Phys. 1997, 106 (5), 1913-1920.

(29) Simon-Kutscher, J.; Gericke, A.; Huhnerfuss, H. Effect of bivalent Ba, Cu, Ni, and Zn cations on the structure of octadecanoic acid monolayers at the air-water interface as determined by external infrared reflection-absorption spectroscopy. Langmuir 1996, 12 (4), 1027-1034.

(30) Sinnamon, B. F.; Dluhy, R. A.; Barnes, G. T. Reflection-absorption FT-IR spectroscopy of pentadecanoic acid at the air/water interface. Colloids Surf., A 1999, 146 (1-3), 49-61.

(31) Nikolova, G. S.; Zhang, L.; Chen, X.; Chi, L.; Haufe, G. Selective synthesis and self-organization at the air/water interface of long chain fluorinated unsaturated ethyl esters and alcohols. Colloids Surf., A 2008, 317 (1-3), 414-420.

(32) Nieto-Suarez, M.; Vila-Romeu, N.; Prieto, I. Influence of different factors on the phase transitions of non-ionic Langmuir monolayers. Appl. Surf. Sci. 2005, 246 (4), 387-391.

(33) Nieto-Suarez, M.; Vila-Romeu, N.; Dynarowicz-Latka, P.; Prieto, I. The influence of inorganic ions on the properties of nonionic Langmuir monolayers. Colloids Surf., A 2004, 249 (1-3), 11-14.

(34) Pelletier, I.; Bourque, H.; Buffeteau, T.; Blaudez, D.; Desbat, B.; Pezolet, M. Study by infrared spectroscopy of ultrathin films of behenic acid methyl ester on solid substrates and at the air/water interface. J. Phys. Chem. B 2002, 106 (8), 1968-1976.

(35) Gericke, A.; Hühnerfussf, H. The conformational order and headgroup structure of long-chain alkanoic acid ester monolayers at the air/water interface. Ber. Bunsenges. Phys. Chem. 1995, 99 (4), 641-650.

(36) Gericke, A.; Huhnerfuss, H. In-situ investigation of saturated long-chain fatty-acids at the airwater-interface by external infared reflection-absorption spectrometry. J. Phys. Chem. 1993, 97 (49), 12899-12908.

(37) Brzozowska, A. M.; Duits, M. H. G.; Mugele, F. Stability of stearic acid monolayers on artificial sea water. Colloids Surf., A 2012, 407, 38-48.

(38) Kester, D. R.; Duedall, I. W.; Connors, D. N.; Pytkowicz, R. M. Preparation of artificial seawater. Limnol. Oceanogr. 1967, 12 (1), 176-179.

(39) Forestieri, S. D.; Staudt, S. M.; Kuborn, T. M.; Faber, K.; Ruehl, C. R.; Bertram, T. H.; Cappa, C. D. Establishing the impact of model surfactants on cloud condensation nuclei activity of sea spray aerosol mimics. Atmos. Chem. Phys. 2018, 18 (15), 10985-11005.

(40) Khattari, Z.; Sayyed, M. I.; Qashou, S. I.; Fasfous, I.; Al-Abdullah, T.; Maghrabi, M. Interfacial behavior of myristic acid in mixtures with DMPC and cholesterol. Chem. Phys. 2017, 490, 106-114. (41) Hao, C. C.; Sun, R. G.; Zhang, J. Mixed monolayers of DOPC and palmitic acid at the liquid-air interface. Colloids Surf., B 2013, 112, 441-445.

(42) Griffith, E. C.; Guizado, T. R.; Pimentel, A. S.; Tyndall, G. S.; Vaida, V. Oxidized aromaticaliphatic mixed films at the air-aqueous solution interface. J. Phys. Chem. C 2013, 117 (43), 2234122350.

(43) Minh Dinh, P.; Lee, J.; Shin, K. Collapsed States of Langmuir Monolayers. J. Oleo Sci. 2016, 65 (5), 385-397.

(44) Kaganer, V. M.; Mohwald, H.; Dutta, P. Structure and phase transitions in Langmuir monolayers. Rev. Mod. Phys. 1999, 71 (3), 779-819.

(45) Hasegawa, T.; Nishijo, J.; Watanabe, M.; Umemura, J.; Ma, Y. Q.; Sui, G. D.; Huo, Q.; Leblanc, R. M. Characteristics of long-chain fatty acid monolayers studied by infrared external-reflection spectroscopy. Langmuir 2002, 18 (12), 4758-4764.

(46) Adams, E. M.; Allen, H. C. Palmitic acid on salt subphases and in mixed monolayers of cerebrosides: Application to atmospheric aerosol chemistry. Atmosphere 2013, 4 (4), 315-336. 
(47) Nutting, G. C.; Harkins, W. D. Pressure-area relations of fatty acid and alcohol monolayers. J. Am. Chem. Soc. 1939, 61, 1180-1187.

(48) Sierra-Hernandez, M. R.; Allen, H. C. Incorporation and exclusion of long chain alkyl halides in fatty acid monolayers at the air-water interface. Langmuir 2010, 26 (24), 18806-18816.

(49) Brzozowska, A.; Mugele, F.; Duits, M. Stability and interactions in mixed monolayers of fatty acid derivatives on artificial sea water. Colloids Surf., A 2013, 433, 200-211.

(50) Yue, X. L.; Steffen, P.; Dobner, B.; Brezesinski, G.; Mohwald, H. Monolayers of mono- and bipolar palmitic acid derivatives. Colloids Surf., A 2004, 250 (1-3), 57-65.

(51) Gershevitz, O.; Sukenik, C. N. In situ FTIR-ATR analysis and titration of carboxylic acidterminated SAMs. J. Am. Chem. Soc. 2004, 126 (2), 482-483.

(52) Johann, R.; Vollhardt, D. Texture features of long-chain fatty acid monolayers at high $\mathrm{pH}$ of the aqueous subphase. Mater. Sci. Eng., C 1999, 8, 35-42.

(53) Wang, L.; Jacobi, S.; Sun, J.; Overs, M.; Fuchs, H.; Schaefer, H. J.; Zhang, X.; Shen, J.; Chi, L. Anisotropic aggregation and phase transition in Langmuir monolayers of methyl/ethyl esters of 2, 3dihydroxy fatty acids. J. Colloid Interface Sci. 2005, 285 (2), 814-820.

(54) Wang, Y.; Du, X.; Guo, L.; Liu, H. Chain orientation and headgroup structure in Langmuir monolayers of stearic acid and metal stearate (Ag, Co, $\mathrm{Zn}$, and $\mathrm{Pb}$ ) studied by infrared reflectionabsorption spectroscopy. J. Chem. Phys. 2006, 124 (13), 134706.

(55) Chen, Q. B.; Kang, X. L.; Li, R.; Du, X. Z.; Shang, Y. Z.; Liu, H. L.; Hu, Y. Structure of the Complex Monolayer of Gemini Surfactant and DNA at the Air/Water Interface. Langmuir 2012, 28 (7), 3429-3438.

(56) Pelletier, I.; Laurin, I.; Buffeteau, T.; Desbat, B.; Pézolet, M. Infrared study of the molecular orientation in ultrathin films of behenic acid methyl ester: comparison between single LangmuirBlodgett monolayers and spin-coated multilayers. Langmuir 2003, 19 (4), 1189-1195.

(57) Muro, M.; Itoh, Y.; Hasegawa, T. A conformation and orientation model of the carboxylic group of fatty acids dependent on chain length in a Langmuir monolayer film studied by polarizationmodulation infrared reflection absorption spectroscopy. J. Phys. Chem. B 2010, 114 (35), 1149611501.

(58) Levin, I. W.; Thompson, T. E.; Barenholz, Y.; Huang, C. Two types of hydrocarbon chain interdigitation in sphingomyelin bilayers. Biochemistry 1985, 24 (22), 6282-6286.

(59) Aoki, P. H. B.; Morato, L. F. C.; Pavinatto, F. J.; Nobre, T. M.; Constantino, C. J. L.; Oliveira, O. N., Jr. Molecular-Level Modifications Induced by Photo-Oxidation of Lipid Monolayers Interacting with Erythrosin. Langmuir 2016, 32 (15), 3766-3773.

(60) Huang, C. H.; Lapides, J. R.; Levin, I. W. Phase-transition behavior of saturated, symmetric chain phospholipid-bilayer dispersions determined by Raman-spectroscopy-correlation between spectral and thermodynamic parameters. J. Am. Chem. Soc. 1982, 104 (22), 5926-5930.

(61) Sakai, H.; Umemura, J. Molecular orientation in Langmuir films of 12-hydroxystearic acid studied by infrared external-reflection spectroscopy. Langmuir 1998, 14 (21), 6249-6255.

(62) Le Calvez, E.; Blaudez, D.; Buffeteau, T.; Desbat, B. Effect of cations on the dissociation of arachidic acid monolayers on water studied by polarization-modulated infrared reflection-absorption spectroscopy. Langmuir 2001, 17 (3), 670-674.

(63) Avila, L.; Saraiva, S.; Oliveira, J. Stability and collapse of monolayers of stearic acid and the effect of electrolytes in the subphase. Colloids Surf., A 1999, 154 (1-2), 209-217.

(64) Griffith, E. C.; Adams, E. M.; Allen, H. C.; Vaida, V. Hydrophobic collapse of a stearic acid film by adsorbed l-phenylalanine at the air-water interface. J. Phys. Chem. B 2012, 116 (27), 78497857.

(65) Gilman, J. B.; Tervahattu, H.; Vaida, V. Interfacial properties of mixed films of long-chain organics at the air-water interface. Atmos. Environ. 2006, 40 (34), 6606-6614. 
645 (66) Gilman, J. B.; Eliason, T. L.; Fast, A.; Vaida, V. Selectivity and stability of organic films at the 646 air-aqueous interface. J. Colloid Interface Sci. 2004, 280 (1), 234-243.

647 (67) Tervahattu, H.; Juhanoja, J.; Kupiainen, K. Identification of an organic coating on marine aerosol 648 particles by TOF-SIMS. J. Geophys. Res.: Atmos. 2002, 107 (D16), 4319.

649 (68) Noziere, B.; Baduel, C.; Jaffrezo, J.-L. The dynamic surface tension of atmospheric aerosol 650 surfactants reveals new aspects of cloud activation. Nat. Commun. 2014, 5, 3335.

651 (69) Farmer, D. K.; Cappa, C. D.; Kreidenweis, S. M. Atmospheric Processes and Their Controlling 652 Influence on Cloud Condensation Nuclei Activity. Chem. Rev. 2015, 115 (10), 4199-4217.

653 (70) Gorbunov, B.; Hamilton, R.; Clegg, N.; Toumi, R. Water nucleation on aerosol particles 654 containing both organic and soluble inorganic substances. Atmos. Res. 1998, 48, 271-283. 